\title{
Distinct Populations of Basal Keratinocytes Express Stromelysin-1 and Stromelysin-2 in Chronic Wounds
}

Ulpu K. Saarialho-Kere, ${ }^{\star}$ Alice P. Pentland, ${ }^{\star}$ Henning Birkedal-Hansen, ${ }^{5}$ William C. Parks, ${ }^{*}$ and Howard G. Welgus ${ }^{\star}$

Divisions of Dermatology at *Jewish Hospital, Washington University Medical Center, and ${ }^{\ddagger}$ Washington University School of Medicine, St. Louis, Missouri 63110; and ${ }^{\S}$ Department of Oral Biology, University of Alabama at Birmingham, Birmingham, Alabama 35294

\begin{abstract}
Wound repair involves cell migration and tissue remodeling, and these ordered and regulated processes are facilitated by matrix-degrading proteases. We reported that interstitial collagenase is invariantly expressed by basal keratinocytes at the migrating front of healing epidermis (Saarialho-Kere, U. K., E. S. Chang, H. G. Welgus, and W. C. Parks. 1992. J. Clin. Invest. 90:1952-1957). Because of the limited substrate specificity of collagenase, principally for interstitial fibrillar collagens, other enzymes must also be produced in the wound environment to effectively restructure tissues with a complex matrix composition. Stromelysins-1 and -2 are closely related, yet distinct metalloproteinases, and both can degrade many noncollagenous connective tissue macromolecules. Using in situ hybridization and immunohistochemistry, we found that both stromelysins are produced by distinct populations of keratinocytes in a variety of chronic ulcers. Stromelysin-1 mRNA and protein were detected in basal keratinocytes adjacent to but distal from the wound edge in what probably represents the sites of proliferating epidermis. In contrast, stromelysin-2 mRNA was seen only in basal keratinocytes at the migrating front, in the same epidermal cell population that expresses collagenase. Stromelysin-1-producing keratinocytes resided on the basement membrane, whereas stromelysin-2-producing keratinocytes were in contact with the dermal matrix. Furthermore, stromelysin-1 expression was prominent in dermal fibroblasts, whereas no signal for stromelysin- 2 was seen in any dermal cell. These findings demonstrate that stromelysins1 and -2 are produced by different populations of basal keratinocytes in response to wounding and suggest that these two matrix metalloproteinases serve distinct roles in tissue repair. (J. Clin. Invest. 1994. 94:79-88.) Key words: stromelysin - metalloproteinases - keratinocytes - wound healing $\bullet$ ulcers
\end{abstract}

\section{Introduction}

The matrix metalloproteinase family, which includes two collagenases, two forms of gelatinases, three stromelysins, matrilysin, and a metalloelastase, consists of structurally related zinc-

Address correspondence to H. G. Welgus, M.D., Division of Dermatology, Jewish Hospital, 216 S. Kingshighway Blvd., St. Louis, MO 63110. Received for publication 4 October 1993 and in revised form 24 December 1993.

J. Clin. Invest.

(C) The American Society for Clinical Investigation, Inc.

0021-9738/94/07/0079/10 \$2.00

Volume 94 , July $1994,79-88$ dependent enzymes. Acting together at physiological $\mathrm{pH}$, these proteinases can degrade all the components of extracellular matrix. Besides participating in normal connective tissue homeostasis and developmental remodeling, the proteolytic activity of matrix metalloproteinases contributes significantly to the tissue damage that occurs in chronic inflammatory diseases, such as rheumatoid arthritis and osteoarthritis $(1,2)$, as well as in tumor invasion (3). Metalloproteinases are produced by multiple cell types, and typically, enzyme expression is tightly regulated and limited to periods of active remodeling. The cell type-specific expression of metalloproteinases is regulated by various factors, including cell-matrix interactions, growth factors and cytokines, lipid mediators, tumor promoters, and inflammatory agents such as bacterial lipopolysaccharide (3).

Stromelysins- 1 and -2 are closely related yet distinct members of the metalloproteinase gene family. Stromelysin-1 was initially characterized in rabbit synovial fibroblasts (4) and is typically expressed by interstitial resident cells. In contrast, stromelysin- 2 was identified in a human adenocarcinoma cDNA library (5) suggesting that these related proteins can be produced by separate cell types. Indeed, as shown recently by one of us, stromelysin-2 is selectively induced in neonatal foreskin keratinocytes but is not expressed by fibroblasts, which, however, do produce stromelysin-1 (6). Stromelysins-1 and -2 are $82 \%$ homologous at the amino acid level (7). Indeed, both stromelysins have a very similar and broad substrate specificity, being able to degrade proteoglycans, types IV and IX collagens, laminin, fibronectin, and the globular domains of procollagens I and III (8). Their expression, however, is regulated by distinct pathways. Stromelysin-1 production is readily stimulated by a variety of growth factors and cytokines, including interleukin1 and PDGF, whereas stromelysin-2 expression is largely unaffected by these agents (9). Human fibroblasts produce high levels of stromelysin-1, but only negligible amounts of stromelysin-2 (9). Thus, in disease situations and in the normal response to injury, these proteins may be expressed by different cell populations and serve distinct functions.

Wound healing involves an orderly series of events which requires extracellular matrix degradation, cell migration, matrix resynthesis, and tissue remodeling. We have shown that interstitial collagenase is consistently expressed at high levels by actively migrating keratinocytes during the re-epithelialization of various types of ulcers $(10,11)$. This spatially distinct and invariant localization indicates that this enzyme has an essential role in wound repair, possibly by affecting the removal of damaged tissue or facilitating the migration of keratinocytes over dermal connective tissue and through the wound bed. However, interstitial collagenase has a very restricted substrate specificity, namely, types I and III collagen, whereas the composition of the papillary dermis and the provisional wound matrix, both of which the migrating keratinocyte encounters, is complex. Therefore, other enzymes must also be involved during the 
healing of wounds and ulcerations to effectively remodel the multiple extracellular matrix molecules which are present. Since stromelysins- 1 and -2 have a broad substrate specificity, including interstitial and basement membrane proteins, and since they can activate procollagenase $(8,12,13)$, we decided to study their expression in chronic ulcers. Here we demonstrate that stromelysins- 1 and -2 are actively expressed by keratinocytes during wound healing but by spatially distinct populations of cells. Furthermore, dermal fibroblasts in the wound bed also express stromelysin-1, whereas production of stromelysin-2 is confined to the epidermis.

\section{Methods}

Tissues. Formalin-fixed, paraffin-embedded specimens were obtained from the Department of Pathology at Jewish Hospital, Washington University Medical Center. 16 ulcers of various etiologies and 10 ulcerated pyogenic granulomas from different parts of the body were studied. Five specimens were stasis ulcers, five were decubitus ulcers, one was pyoderma gangrenosum, and one specimen exhibited marked fibrosis. Five ulcers were nonspecific, characterized only by inflammation and granulation tissue. Five samples of normal skin from different parts of the body were also examined.

In situ hybridization. In situ hybridization was performed on 5- $\mu \mathrm{m}$ sections as described in detail by Prosser et al. (14). All samples were treated with proteinase $\mathrm{K}$ and were washed in $0.1 \mathrm{M}$ triethanolamine buffer containing $0.25 \%$ acetic anhydride. Sections were covered with $25-50 \mu$ l of hybridization buffer containing $2.5 \times 10^{4} \mathrm{cpm} / \mu \mathrm{l}$ of ${ }^{35} \mathrm{~S}$ labeled antisense or sense RNA probe. Sections were incubated at $55^{\circ} \mathrm{C}$ for $18 \mathrm{~h}$ in a humidified chamber. After hybridization, slides were washed under stringent conditions, including treatment with RNase A to remove unhybridized probe, and were processed for autoradiography as described (14). After 10-21 d of autoradiographic exposure, the photographic emulsion was developed, and slides were stained with hematoxylin-eosin. The sections chosen for presentation in this report were exposed for $13 \mathrm{~d}$.

$R N A$ probes. The production and specificity of the antisense human interstitial collagenase RNA probe has been described $(10,15)$. A full length human stromelysin-1 cDNA (16) was provided by Dr. Markku Kurkinen (Wayne State University, Detroit, MI) and we subcloned a $217 \mathrm{bp}$ EcoRI-XhoI fragment coding an unique portion of the 3' untranslated region (UTR) into a Bluescript KSII+ plasmid (Stratagene, La Jolla, CA). A 175-bp fragment, corresponding to positions 1568 to 1743, which code for unique sequences of the $3^{\prime}$ UTR of the human stromelysin-2 cDNA, was generated by polymerase chain reaction and was designed with a T7 RNA polymerase recognition element at the $5^{\prime}$ end and an SP6 RNA polymerase recognition element at the $3^{\prime}$ end (6). As a control for nonspecific hybridization, sections in each experiment were hybridized with ${ }^{35} \mathrm{~S}$-labeled sense RNA transcribed from a bovine tropoelastin cDNA. The validity of this probe as a negative control has been confirmed by Northern (14) and by in situ hybridization assays $(10,11,17)$. In vitro transcribed RNA was labeled to high specific activity with $\left[{ }^{35} \mathrm{~S}\right] \mathrm{UTP}(>1,200 \mathrm{Ci} / \mathrm{mmole})$ as described (11).

Assessment of probe specificity. Expression of stromelysin-1 mRNA was stimulated in CRL-1885 and CRL-1900 human fibroblast cell lines (American Tissue Culture Center, Bethesda, MD) by exposure to 15 $\mathrm{ng} / \mathrm{ml}$ of phorbol myristate acetate and $20 \mathrm{U} / \mathrm{ml}$ of interleukin-1 for 72 $h$ in serum-free lactalbumin-containing medium as described (18). As a source of stromelysin-2 mRNA, U937 cells, a human monocytic line, were stimulated with $1.6 \times 10^{-8} \mathrm{M}$ PMA and $2.5 \mu \mathrm{g} / \mathrm{ml}$ of bacterial endotoxin (Sigma Chemical Co., St. Louis, MO) for 48 h (19). RNA isolation and Northern hybridization were done as described (20), and the stringency conditions were similar to those for the in situ hybridization assay. Gel-purified cDNA fragments were labeled with $\alpha-\left[{ }^{32} \mathrm{P}\right]-$ dCTP by random priming.

Keratinocyte culture. Human keratinocytes were obtained from re- duction mammoplasties and were cultured as described (21). Cells were plated onto P100 dishes coated with $0.75 \mathrm{mg} / \mathrm{ml}$ type I collagen (Vitrogen 100; Celtrix Laboratories, Palo Alto, CA), and after reaching confluence, were washed, refed, and harvested $72 \mathrm{~h}$ later for RNA isolation.

Antibodies. Polyclonal antiserum was generated by immunizing rabbits with purified human stromelysin-1 isolated from activated fibroblasts (18). The specificity of this antibody has been demonstrated by immunoblotting and immunoprecipitation (22). To minimize potentia background, the stromelysin-1 antibody was purified by affinity chromatography. Stromelysin-1 was coupled to Affi-Gel 100 (Bio Rad Laboratories, Richmond, CA), antiserum adsorbed to the column, and specific antibody eluted with $0.2 \mathrm{M}$ glycine, $\mathrm{pH} 2.3$, as described (23). Direct ELISA confirmed that essentially all immunoreactivity was recovered, and the collected fractions were dialyzed and concentrated in $0.1 \mathrm{M}$ Tris, $\mathrm{pH} 7.5$, at $2 \%$ of their original volume. Antihuman $\alpha 1$ (IV) collagen monoclonal antibody was supplied by Dr. John A. McDonald (Mayo Clinic, Scottsdale, AZ). This antibody was raised against the $\mathrm{NH}_{2}$ terminal domain of the molecule, is specific as determined by ELISA and immunoblotting (Dr. Edmond C. Crouch, personal communication), and we have used it in our previous studies (11). Tissue macrophages were identified using a monoclonal antibody (KP-1; Dako Corp., Carpinteria, CA) which reacts with CD-68, a specific macrophage marker (24).

ELISA. Interstitial collagenase content of conditioned media samples was quantified by indirect competition ELISA, as we described previously (25). Stromelysin-1 protein levels were quantified by ELISA using a rabbit anti-human polyclonal antiserum (18) and conditions identical to those for the collagenase assay. The stromelysin-1 ELISA exhibited a sensitivity of $\sim 20 \mathrm{ng} / \mathrm{ml}$ and measured total enzyme present, whether free or bound to susceptible substrates or TIMP. Importantly, this ELISA was completely specific for stromelysin-1, even though the antibody was generated against the intact native protein. When $1 \mu \mathrm{g} / \mathrm{ml}$ of stromelysin-2 was included in this ELISA, no competition for the stromelysin-1 antibody was detected. Furthermore, interstitial collagenase, matrilysin, and $92-\mathrm{kD}$ gelatinase were also not recognized. The complete specificity of this assay for stromelysin-1 and lack of cross reactivity for stromelysin- 2 may be due to the large dilution $(1: 7,500)$ of antibody.

Immunohistochemistry. Immunostaining was performed on sections serial to those used for in situ hybridization. Type IV collagen was detected by the peroxidase-antiperoxidase technique with diaminobenzidine (DAB) as a chromogenic substrate (11). Double immunostaining for stromelysin-1 and CD-68 was performed using reagents from Vector Laboratories, Inc. (Burlingame, CA). Endogenous peroxidase was blocked by incubation with $0.3 \% \mathrm{H}_{2} \mathrm{O}_{2}$ for $30 \mathrm{~min}$ at room temperature and $10 \mathrm{mg} / \mathrm{ml}$ trypsin was applied to the slides for $30 \mathrm{~min}$. The affinity purified stromelysin-1 antibody was diluted 1:500 and incubated on sections at $4^{\circ} \mathrm{C}$ overnight. Stromelysin- 1 was detected by the avidinbiotin peroxidase technique (Vectastain ABC Kit; Vector Labs, Inc., Burlingame, $C A$ ) with DAB as a chromogenic substrate. Next, the CD68 macrophage antibody was diluted 1:300 and incubated on sections at $37^{\circ} \mathrm{C}$ for $1 \mathrm{~h}$; macrophages were identified by the avidin-alkaline phosphatase technique (Vectastain ABC-AP Kit) using Fast Red as a chromogenic substrate. With this protocol, stromelysin-1-producing cells stained brown, and CD-68 positive macrophages were bright red. Sections were counterstained with Harris hematoxylin. Controls were performed with the appropriate rabbit preimmune serum or preimmune mouse ascites fluid.

\section{Results}

Probe specificity. Because of the significant sequence homology between the translated sequences of the stromelysin-1 and stromelysin-2 mRNAs (7), we needed to use highly specific probes for our in situ hybridization assays. Since the $3^{\prime}$ UTRs of these related metalloproteinase transcripts are quite distinct 


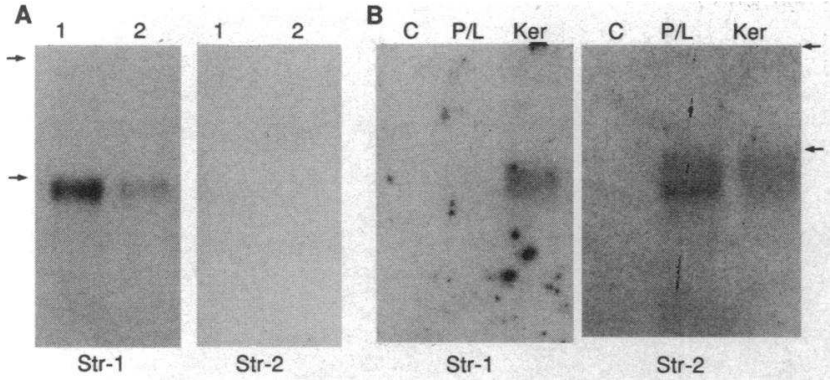

Figure 1. Demonstration of specificity of the stromelysin-1 and stromelysin-2 probes by northern hybridization. $(A)$ Expression of stromelysin-1 mRNA was stimulated in the human fibroblast cell lines CRL-1885 (lanes 1) and CRL-1900 (lanes 2) by exposure to both phorbol ester and interleukin-1 as described in Methods. These cells do not express stromelysin-2. Total RNA ( $10 \mu \mathrm{g}$ per lane) was resolved through agarose-formaldehyde gels and transferred to nitrocellulose. Blots were hybridized with ${ }^{32} \mathrm{P}$-labeled cDNAs of fragments complementary to the 3' UTRs of stromelysin-1 (Str-1) or stromelysin-2 (Str-2) mRNAs. The autoradiogram shows that the stromelysin-1 probe detected the appropriate $1.9-\mathrm{kb}$ mRNA and that the stromelysin- 2 probe did not crosshybridize with stromelysin-1 mRNA. Autoradiography was for $18 \mathrm{~h}$. $(B)$ Expression of stromelysin-2 mRNA was stimulated in U937 cells by exposure to both phorbol ester and lipopolysaccharide $(P / L)$ as described in Methods. Northern blots ( $10 \mu \mathrm{g}$ per lane) were hybridized with the same probes as $A$. No hybridization signal was detected in control U937 cells $(C)$, and only signal for stromelysin-2 mRNA was detected in the stimulated cells. Primary human keratinocytes plated on native type I collagen expressed both stromelysin mRNAs. Arrows in both panels mark the migration of the 28 and $18 \mathrm{~s}$ rRNA subunits. Autoradiography was for $3 \mathrm{~d}$.

(7), we used probes complementary to these sequences as described in Methods. Computer analysis showed no extended similarity between these two 3' UTRs and an overall homology of only $56.1 \%$. To verify further the specificity of these probes, we used Northern hybridization with RNA samples known to contain stromelysin-1 and stromelysin- 2 mRNA. As expected, stromelysin-1 cDNA hybridized only to a $1.9-\mathrm{kb}$ mRNA with RNA isolated from phorbol ester-stimulated fibroblasts, but no signal was detected on fibroblast RNA blots hybridized with the stromelysin- 2 probe (Fig. $1 \mathrm{~A}$ ). Even after an extended autoradiographic exposure of $7 \mathrm{~d}$, no signal for stromelysin-2 mRNA was seen in the fibroblast samples. In contrast, stromelysin-2 mRNA was detected in RNA isolated from activated U937 cells, but no signal for stromelysin-1 mRNA was seen in this sample (Fig. $1 B$ ). Neither mRNA was detected in RNA from control U937 cells. These results confirm the specificity of these probes for the appropriate mRNA. Furthermore, as demonstrated by Southern analysis, the stromelysin-1 probe does not cross-hybridize with full-length collagenase cDNA (10).

Expression of stromelysin-1 in chronic ulcers. The presence of stromelysin-1 mRNA was studied by in situ hybridization in 16 chronic ulcers of various etiologies including venous stasis, pyoderma gangrenosum, and decubitus (see Methods), and also in seven ulcerated pyogenic granulomas. Signal for stromelysin1 mRNA was detected in keratinocytes in 17 of these 23 lesions (Table I). In addition, stromelysin-1 mRNA was seen in 18/ 23 specimens within cells of the dermal granulation tissue. Two of the stromelysin-1-negative lesions were pyogenic granulomas, and two of the four negative ulcers were characterized by fibrosis; all of the stromelysin-1-negative samples exhibited comparatively little inflammation. When seen in the epidermis, stromelysin-1 mRNA was expressed by basal keratinocytes (Fig. 2, A-C, medium arrows) in the vicinity of the ulceration, but the positive cells preceded the migrating front of keratinocytes, which is demarcated by large arrows. This was a consistent finding in all specimens exhibiting stromelysin-1 production by keratinocytes (also see Fig. 3 ). As shown by Northern hybridization (Fig. $1 B$ ), isolated human keratinocytes retain the ability to express stromelysin-1 in culture.

Expression of stromelysin-1 in dermal fibroblasts. Strong signal for stromelysin-1 mRNA was also seen in many dermal cells in most samples (Fig. 2, $A$ and $C$, arrowheads; Fig. 4; and Table I), and under higher magnification these positive cells had a fibroblastic morphology (Fig. 2, A, inset 2, arrowheads). To identify the dermal cells expressing stromelysin-1 mRNA, we used a double immunostaining assay. Stromelysin1 -producing cells were localized by reactivity with an affinitypurified antibody using DAB as a chromogen, which forms a brown precipitate. Since macrophages can produce stromelysin1 in vitro, these cells were identified by staining for CD-68, a macrophage-specific marker, using Fast Red as a reporter. In agreement with the in situ hybridization findings, basal keratinocytes contained stromelysin-1 protein (Fig. $2 D$ ), whereas redstained dermal macrophages were uniformly negative (Fig. 2, $D$ and $E$, small arrows). In the dermis, many spindle-shaped fibroblast-like cells had strong immunoreactivity for stromelysin-1 (Fig. 2 E, arrowheads). No staining was seen in sections processed with nonimmune serum or without primary antibody (data not shown). Thus, based on morphology and the pattern of immunostaining, we conclude that fibroblasts are the princi-

Table I. Expression of Metalloproteinases in Chronic Ulcers*

\begin{tabular}{|c|c|c|c|c|c|c|}
\hline & \multicolumn{2}{|c|}{ Collagenase } & \multicolumn{2}{|c|}{ Stromelysin-1 } & \multicolumn{2}{|c|}{ Stromelysin-2 } \\
\hline & Ulcers $^{\ddagger}$ & $\begin{array}{l}\text { Ulcerative } \\
\text { pyogenic } \\
\text { granuloma }\end{array}$ & Ulcers ${ }^{\ddagger}$ & $\begin{array}{l}\text { Ulcerative } \\
\text { pyogenic } \\
\text { granuloma }\end{array}$ & Ulcers $^{*}$ & $\begin{array}{l}\text { Ulcerative } \\
\text { pyogenic } \\
\text { granuloma }\end{array}$ \\
\hline \multicolumn{7}{|l|}{ Keratinocytes } \\
\hline Migrating & $16 / 16$ & $10 / 10$ & $0 / 16$ & $0 / 7$ & $4 / 11$ & $3 / 3$ \\
\hline Proliferating & $0 / 16$ & $0 / 10$ & $12 / 16$ & $5 / 7$ & $0 / 11$ & $0 / 3$ \\
\hline Dermis & $16 / 16$ & $7 / 10$ & $14 / 16$ & $4 / 7$ & $0 / 11$ & $0 / 3$ \\
\hline
\end{tabular}

* The number of samples with a positive signal for the various metalloproteinase mRNAs is listed relative to the total number of different samples hybridized with a given probe. ${ }^{\ddagger}$ Includes venous stasis, decubitus, pyoderma gangrenosum, and nonspecific ulcers. 

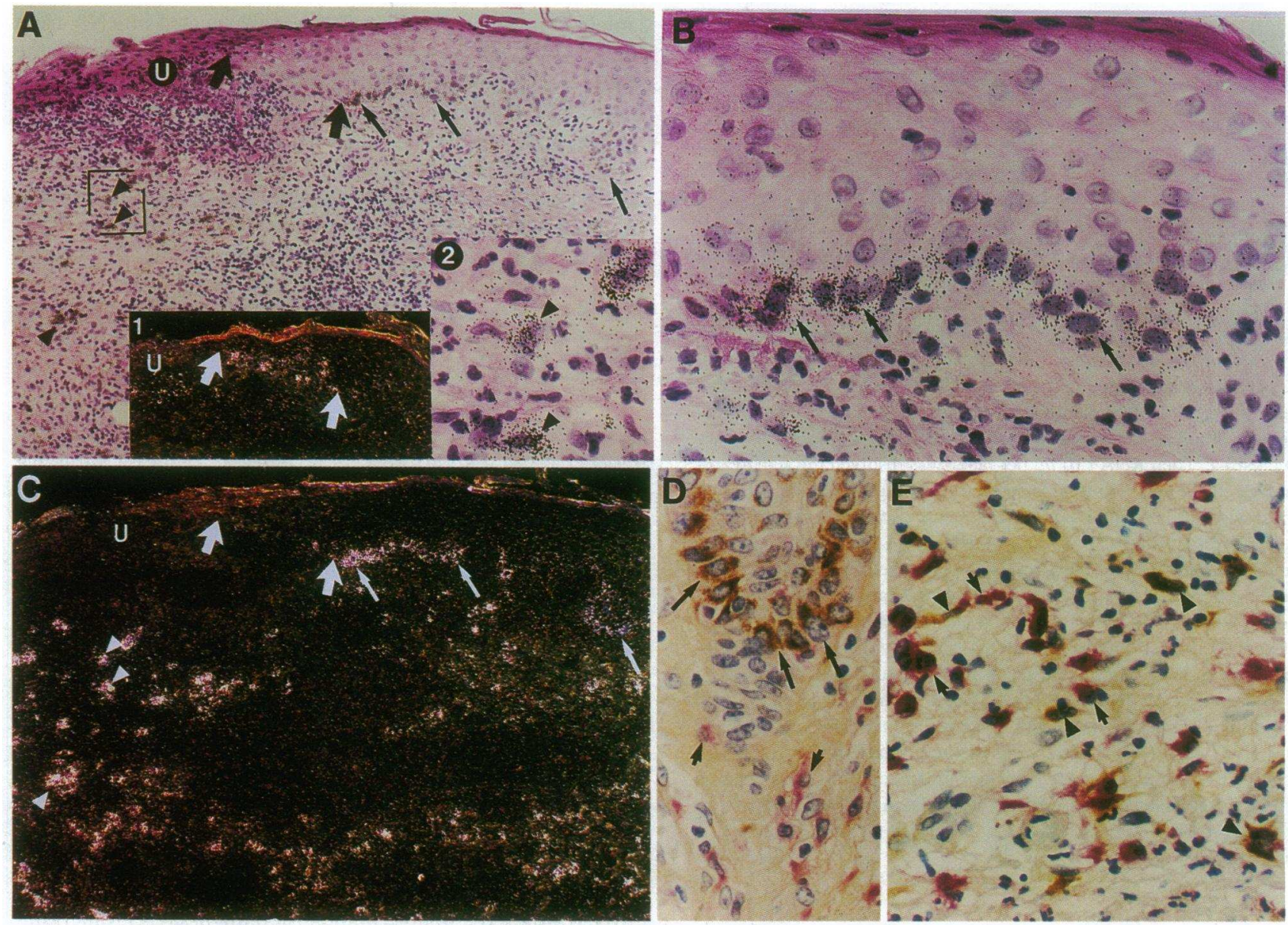

Figure 2. Expression of stromelysin-1 by basal keratinocytes and dermal fibroblasts in chronic ulcers. $(A-C)$ Sections of a nonspecific ulcer were processed for in situ hybridization with an ${ }^{35} \mathrm{~S}$-labeled antisense RNA probe for stromelysin-1 mRNA. The migrating front of the epidermis is indicated by large arrows and is seen adjacent to an ulceration $(U)$ in the upper left corner. With dark-field illumination $(C)$, signal for stromelysin1 mRNA was seen in the epidermis (medium arrows) away from the migrating front of epithelium, and signal became progressively weaker in basal cells located even further away from the wound site. Under higher magnification $(B)$, the epidermal signal was confined to basal keratinocytes. The location of stromelysin-1-positive epidermal cells was quite distinct from the sites of collagenase expression by keratinocytes, which was always seen in cells bordering the wound edge (inset 1). Signal for stromelysin-1 was also seen in many cells in the dermis (arrowheads mark a few positive calls), which under higher magnification had a morphology consistent with that of fibroblasts (bracketed area in $A$ is enlarged in inset 2). (D) Sections were sequentially immunostained for stromelysin-1 using an affinity-purified antibody and DAB as a chromogen, which forms a brown precipitate, then for CD-68, a macrophage-specific marker, using Fast Red as a reporter. Shown is a view of the intact epidermis adjacent to the area of re-epithelialization. In agreement with the in situ hybridization findings $(B)$, stromelysin-1 protein was detected in basal keratinocytes (medium arrows). Macrophages (small arrows) had no immunoreactivity for stromelysin-1 protein. $(E)$ In the dermis underlying an ulceration, immunoreactivity for stromelysin-1 (arrowheads) is distinct from that for macrophages (small arrows).

pal cell producing stromelysin-1 in the dermal granulation tissue.

Distinct localization of stromelysin-1 and collagenase expression. As we reported previously, collagenase is produced by keratinocytes at the leading edge of the wound. This area is bordered by the large arrows in Fig. $2, A$ and $C$, and as seen in a serial section, basal keratinocytes at the wound edge are positive for collagenase mRNA (Fig. $2 C$, inset 1 ; also see Fig. 3 and 4). In contrast, as discussed above, expression of stromelysin-1 by keratinocytes was confined to basal cells that were adjacent to but behind the migrating population of keratinocytes (Fig. 2 $C$, medium arrows). To directly compare the spatial expression of these metalloproteinases, we hybridized serial sections of the same samples for collagenase and stromelysin-1 mRNAs (Fig. 3 ). In the sample shown, an ulcer $(U)$ is located in the upper right hand corner, and normal-appearing, intact epidermis is seen to the left of the wound. Higher magnification dark-field illuminated views of the areas adjacent to and removed from the ulcer are shown in the middle panels on the right and left, respectively. In these micrographs, the white dotted line marks the epidermal-dermal border (Fig. 3). As was seen in Fig. 2, stromelysin-1 mRNA was expressed by basal keratinocytes away from the wound edge and was not detected in epidermal cells proximal to the ulcer. In contrast, collagenase mRNA was seen in basal keratinocytes at the wound edge but not in the more distal epidermal cells. Prominent expression of both stromelysin-1 and collagenase mRNAs was observed in dermal cells both near and removed from the ulcer bed (Fig. 3). No specific signal was seen in sections hybridized with ${ }^{35} \mathrm{~S}$-labeled sense probe (Fig. 3). As we reported previously (11), migrating 

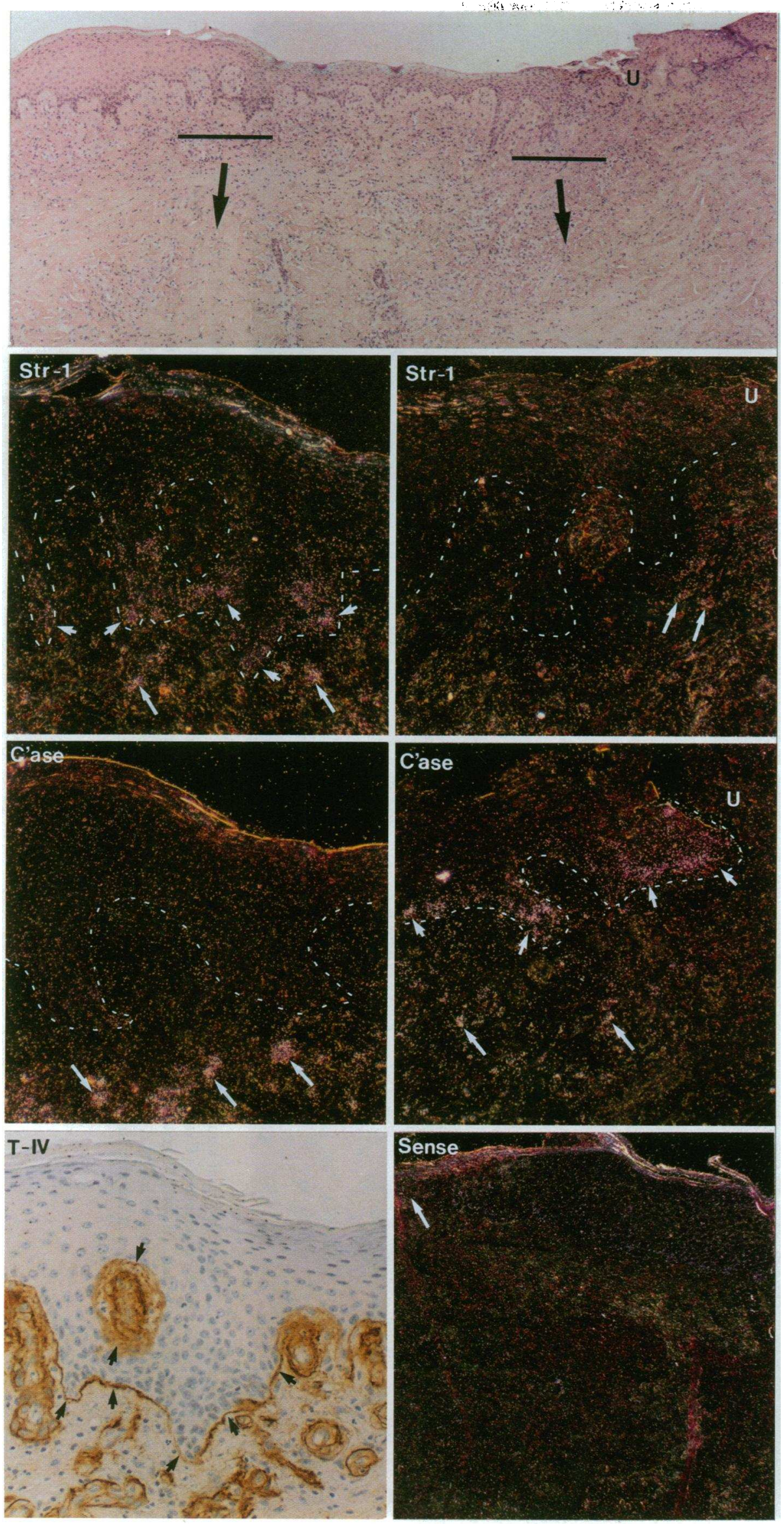

Figure 3. Stromelysin-1 and collagenase are expressed in distinct areas of the healing epidermis. In the top panel, an ulceration $(U)$ with acute inflammation is seen in the upper right hand corner. Serial sections were hybridized with ${ }^{35} \mathrm{~S}$-labeled antisense probes for stromelysin-1 (Str1) or collagenase (C'ase) mRNAs or were immunostained for type IV collagen $(T-I V)$. The solid horizontal lines indicate views that are shown below under dark-field illumination at higher magnification. In these dark-field panels, the white-dashed line demarcates the epidermal-dermal junction. In the right-hand panel, no signal for stromelysin-1 mRNA was detected in the epidermis near to the ulceration, but a few weakly positive cells (long arrows) were seen in the dermal granulation tissue. However, as seen in the left panel, stromelysin-1 mRNA was expressed both by basal keratinocytes (short arrows) away from the ulcer and by dermal cells (long arrows). A serial section was hybridized for collagenase mRNA, which was predictably expressed by basal keratinocytes (short arrows, right panel) near to the ulcer. No collagenase mRNA was detected in epidermal cells away from the ulcer (left panel), although many dermal cells throughout the section expressed the enzyme (long arrows). Sections hybridized with ${ }^{35} \mathrm{~S}$-labeled sense RNA (Sense) had no signal above background. In this photomicrograph, the arrow marks the migrating front of the healing epidermis. Immunostaining for type IV collagen shows an intact basement membrane (arrows) at the site of stromelysin-1 keratinocyte expression. 

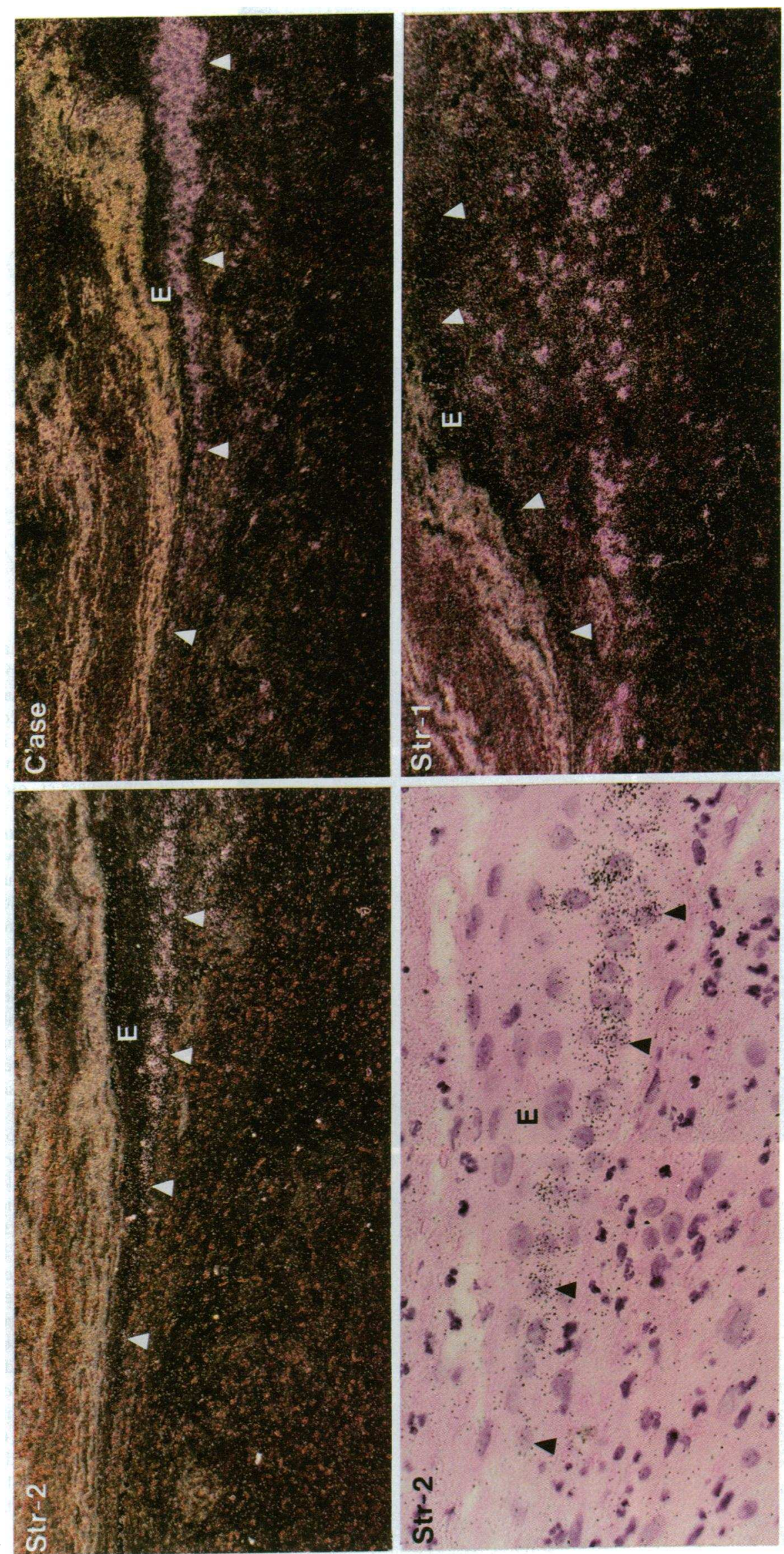

苍芯

过骂

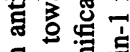

业品

3.

通兽

总包些的

合害条

政

跣

son

解

品觜宫

记

吅猔

a包家

要论

总总密

3 o $>$

㐘焉

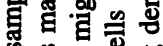

क व 0

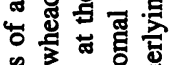

을 올올 遏

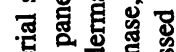

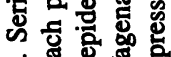

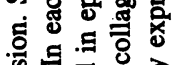

密

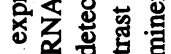

喝

政

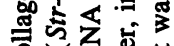

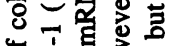

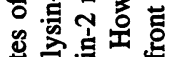

क

के

边

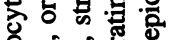

过若

记总要

娄

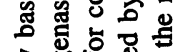

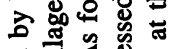

类 象和 खे $\because 2$. 소을

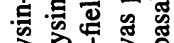

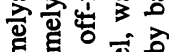
总总总通 $\checkmark$ 总家

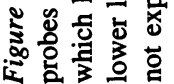


keratinocytes which express collagenase mRNA are in direct contact with the dermal matrix and are not seen on an intact basement membrane. In contrast, stromelysin-1-positive keratinocytes resided on an intact basement membrane, as indicated by staining for type IV collagen (Fig. 3).

Stromelysin-2 and collagenase are expressed by the same population of basal keratinocytes. Our Northern hybridization findings demonstrated that cultured primary keratinocytes express stromelysin- 2 mRNA at levels that were roughly equivalent to those for stromelysin-1 mRNA (Fig. $1 B$ ). We cannot conclude from these results if both stromelysins are expressed by the same cells or if distinct subpopulations express each enzyme separately. To address these possibilities, we localized the expression of stromelysin- 2 in vivo. 11 chronic ulcers and three ulcerated pyogenic granulomas were examined for stromelysin-2 mRNA expression. All pyogenic granulomas and 4/11 ulcers had signal for stromelysin-2 mRNA (Table I), and in all samples, stromelysin- 2 mRNA was detected only in basal epidermal cells. No signal for stromelysin- 2 mRNA was found in dermal cells. Furthermore, as revealed by in situ hybridization of serial sections, stromelysin-2 mRNA was detected in the same population of cells that expressed interstitial collagenase, that is, signal was seen in migrating keratinocytes at the leading edge of the ulcer margin (Fig. 4). In the sections shown (Fig. $4)$, the tapering migrating front of epidermal cells $(E)$ ends at the ulcer edge located just to the left of the field-of-view. In contrast, no signal for stromelysin-1 mRNA was seen in epidermal cells at the migrating epithelial front, but many stromelysin1-positive cells were seen in the underlying dermis (Fig. 4) consistent with the findings discussed above (see Fig. 2 and 3 ). In further similarity to collagenase, stromelysin- 2 was prominently expressed by basal keratinocytes which largely were not in contact with an intact basement membrane (Fig. 5).

Five samples of normal skin from different parts of the body were examined by in situ hybridization for expression of stromelysin-1 and stromelysin-2 mRNAs. No specific signal for either transcript was detected in these control samples (data not shown). Thus, these negative results emphasize the concept that metalloproteinases are generally not constitutively expressed in vivo but rather are induced in response to injury, inflammation, and tumor growth.

\section{Discussion}

Wound healing is a complex biological response leading to epidermal regeneration and dermal repair. The degradation of multiple structural molecules must necessarily accompany wound healing to facilitate basement membrane dissolution, turnover of damaged dermal components, and breakdown of the provisional matrix. We have recently reported that interstitial collagenase is prominently and invariantly expressed in healing associated with ulcerative pyogenic granulomas (10), various other chronic ulcers, and acute wounds (11). However, only a few matrix molecules are cleaved by collagenase, and in the setting of a healing wound, these are probably restricted to native types I and III collagen. Therefore, other metalloproteinases capable of degrading fibronectin, laminin, type IV collagen, and glycosaminoglycans would be required for effective wound repair and tissue remodeling. The in situ hybridization findings we report here suggest that stromelysins- 1 and -2 are the major metalloproteinases responsible for performing these catalytic functions. Our earlier in situ studies (11) showed that
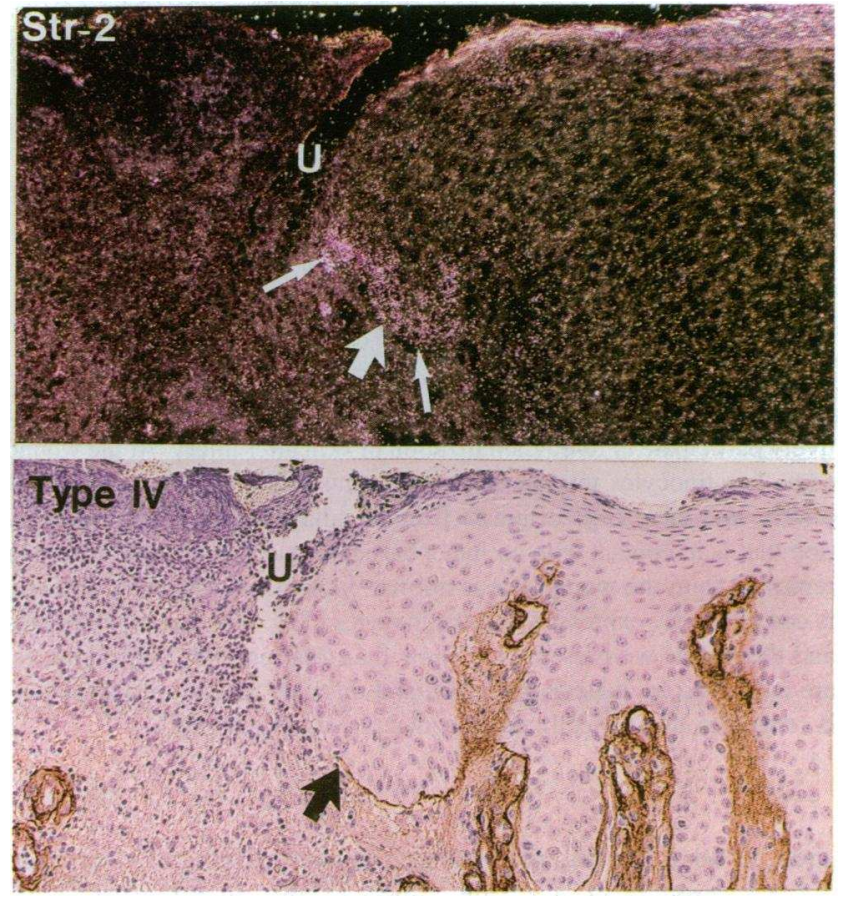

Figure 5. Stromelysin-2 mRNA is expressed by basal keratinocytes which are not in contact with a basement membrane. Serial sections of a stasis ulcer were hybridized with ${ }^{35} \mathrm{~S}$-labeled antisense RNA for stromelysin-2 mRNA (Str-2) or stained with a monoclonal antibody to type IV collagen ( $T$-IV ). (Str-2) Low-power dark-field photomicrograph revealed strong autoradiographic signal for stromelysin-2 mRNA (small arrows) in migrating keratinocytes at the edge of the ulcer $(U)$. The large arrow approximates the extent of the basement membrane. Autoradiographic exposure was for $10 \mathrm{~d}$. ( $T-I V)$ A parallel section was immunostained for type IV collagen to demonstrate that the epidermal basement membrane ceases (arrow) about where stromelysin-2 expression begins. Strong immunostaining is also evident in the basement membrane of multiple blood vessels. $\times 100$.

other matrix metalloproteinases with broad catalytic activity, such as the 92- and 72-kD gelatinases and matrilysin, are not actively synthesized by either resident or inflammatory cells of chronic wounds. Nonetheless, these other proteinases, especially $92-\mathrm{kD}$ gelatinase, may be secreted by certain inflammatory cells which migrate to wound sites, notably neutrophils (26) and eosinophils $(23,27)$.

The expression of stromelysin-1 by keratinocytes in situ is a novel finding, since this enzyme has been thought to be primarily a product of cells of mesodermal origin, such as fibroblasts $(6,18,28)$, endothelial cells $(29)$, and macrophages $(22$, 30 ). The localization of stromelysin-1 expression in chronic ulcers contrasts significantly from the sites of interstitial collagenase production. One major difference we found is that stromelysin-1 is more frequently and prominently expressed by dermal cells than by keratinocytes. On the other hand, collagenase is invariantly and strongly expressed by basal keratinocytes, and although it is often detected in the dermis (Table I), dermal collagenase expression is typically scant and present in only a few cells $(10,11)$ (Fig. 4). Two clear examples of these contrasting sites of expression are seen in Figs. 3 and 4. Since stromelysin- 1 is secreted in vitro by several cell types, we identified the stromelysin-1-producing cells in the dermis of chronic ulcers. Double immunostaining with antisera to stromelysin-1 

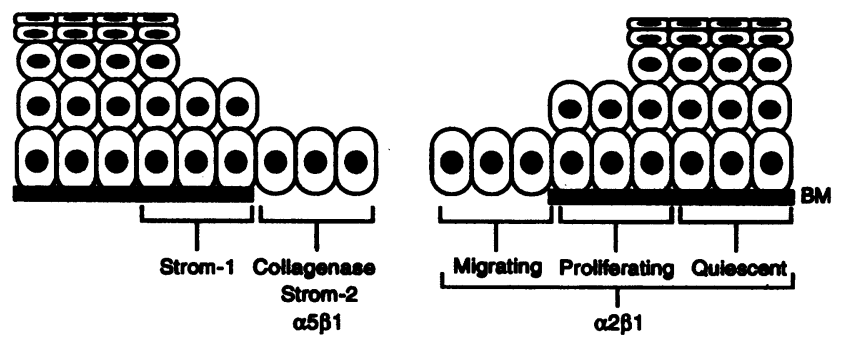

Figure 6. Spatial distribution of metalloproteinase expression in the healing epidermis. At least two populations of basal keratinocytes actively participate in re-epithelialization of skin after injury. At the wound edge, keratinocytes migrate over the dermis and under the provisional matrix, and these cells originate from an adjacent proliferating population that is in contact with an intact basement membrane $(B M)$. Further removed from the wound site is normal, intact skin. The $\alpha 2 \beta 1$ integrin is constitutively expressed on keratinocytes (32). Our previous findings and the results we present here show that different metalloproteinases are expressed by these populations and that this pattern of expression is related to distinct cell:matrix contacts (see Discussion).

and CD-68, a specific macrophage marker, effectively excluded the macrophage as a major source of this metalloproteinase. From their morphology and localization, we conclude that fibroblasts represent the major source of stromelysin-1 production in the dermis.

Another significant difference between stromelysin-1 and collagenase expression is that distinct keratinocyte populations produce these two metalloproteinases. In essence, collagenase production is restricted to keratinocytes at the migrating front of the healing epidermis, whereas stromelysin-1 is expressed by basal cells distal to the wound edge (Fig. 6). Although not established in our studies, the stromelysin-1-positive keratinocytes most likely represent epidermal cells which proliferate and become the migrating cells in response to injury. Proliferation and migration of keratinocytes during re-epithelialization involve distinct populations of cells, and these processes have distinct features. For example, cell migration starts immediately after injury whereas cell proliferation begins $\sim 24 \mathrm{~h}$ later, supplying additional cells for migration and for epidermal differentiation (31). As is discussed below, our results suggest that these keratinocyte populations have separate roles in tissue remodeling associated with healing.

We also found that stromelysin-2 has an unique pattern of expression in wound healing. This novel observation indicates that stromelysin-2 is an important product of human keratinocytes in vivo and provides among the first evidence that this enzyme is involved in normal tissue responses. In chronic wounds, stromelysin- 2 was expressed by basal keratinocytes at the migrating front of the epidermis, the same population of cells that produce interstitial collagenase (Figs. 4, 5, and 6). In contrast to collagenase, however, signal for stromelysin-2 mRNA was never observed in dermal cells either adjacent or distal to the ulcer. These results are consistent with our Northern hybridization data (Fig. $1 \mathrm{~A}$ ) and with cell culture findings of others $(6,7,9)$ showing no or only minor expression of stromelysin- 2 by stimulated fibroblasts.

The distinct spatial distribution of metalloproteinase expression by keratinocytes in ulcer samples indicates that production of these enzymes is regulated by different factors. We recently reported that collagenase is expressed by migrating basal kera- tinocytes at the margin of chronic and acute wounds and that these cells selectively express $\alpha 5 \beta 1$ integrin and are in contact with the dermal matrix rather than the basement membrane (10, 11). Collagenase production is shut off once re-epithelialization is complete and the basement membrane is re-established (11). Based upon these observations, we proposed that altered cell:matrix interactions, specifically keratinocyte contact with a dermal matrix component, induces collagenase expression, whereas cells residing on a basement membrane are constrained from synthesizing this enzyme. Indeed, we demonstrated that collagenase production is induced by isolated keratinocytes grown on a type I collagen substratum, whereas enzyme production is not stimulated by cells cultured on Matrigel, used as a source of basement membrane proteins (11). It is possible that the $\alpha 2 \beta 1$ integrin receptor, which recognizes type I collagen and is constitutively expressed on keratinocytes $(32,33)$, mediates induction of collagenase gene expression. Since keratinocytes are not normally in contact with type I collagen, basal production of $\alpha 2 \beta 1$ may keep keratinocytes primed and ready to respond to wounding.

In most samples (Table I), keratinocytes expressed stromelysin-1 mRNA, and these cells lagged just behind the epidermal front corresponding to the collagenase-producing keratinocytes (Figs. 2, 3, and 6). Furthermore, stromelysin1 -producing keratinocytes were in contact with an underlying basement membrane (Fig. 3). Since both resting keratinocytes in normal skin, which do not produce stromelysin1 , and stromelysin-1-positive keratinocytes in chronic ulcers reside on a basement membrane, the primary stimulus for stromelysin-1 expression in wound healing is probably not cellular interaction with a matrix molecule but rather exposure to a soluble factor. Although the identity of this inducing factor is not known, cytokines such as tumor necrosis factor$\alpha(34)$, interleukin-1 (35), epidermal growth factor $(36,37)$, and platelet-derived growth factor (38) stimulate stromelysin-1 expression in cultured fibroblasts and may also be active on keratinocytes. Alternatively, TGF- $\beta 1$ may be involved. Interestingly, this cytokine downregulates metalloproteinase expression in interstitial cells, such as fibroblasts and chondrocytes (39), but augments enzyme production by keratinocytes ( 6 and our unpublished observations).

Since stromelysin-2 and interstitial collagenase were expressed by the same cells (Figs. 4 and 6), contact of actively migrating keratinocytes with the dermal matrix may influence production of both these enzymes. Indeed, our Northern hybridization findings demonstrate that stromelysin-2 was expressed in keratinocytes cultured on a type I collagen substratum (Fig. $1 B$ ). Furthermore, stromelysin-2-positive keratinocytes did not reside on an intact basement membrane (Fig. 5) indicating that altered cell-matrix contacts may be an important determinant in regulating expression of this metalloproteinase. Similar to what we found for collagenase (11), the border between immunoreactive basement membrane and stromelysin-2-positive basal keratinocytes was not precise; however, the signal for stromelysin2 mRNA decreased progressively within a few cells overlying the newly formed basement membrane. This observation is consistent with our idea that cell-matrix interactions maintain the phenotype of basal keratinocytes in intact skin and indicates that stromelysin- 2 expression ceases once the cell establishes contact with the basement membrane. Whatever does control stromelysin-2 production in keratinocytes, 
it is likely to be different from what regulates stromelysin1 expression, especially in light of the distinct localization of these enzymes in the wound environment. Although both enzymes share a high degree of amino acid sequence homology and similar proteolytic properties, the promoter regions of these two genes are quite disparate (7). Thus, whereas stromelysin-1 is synthesized by many cell types and is by stimulated a variety of cytokines, stromelysin- 2 production is seemingly more limited and may be confined to epithelial cells (6).

The distinct localization of collagenase and stromelysin-1 and -2 expression suggest that these enzymes are responsible for different functions in wound healing. In the dermis, collagenase and stromelysin-1 probably affect tissue repair at multiple stages, including remodeling during the formation and removal of granulation tissue and during the resolution of scar tissue. In the epidermis, however, collagenase may be used to promote keratinocyte migration as well as to remodel dermal connective tissue. Stromelysin- 2 may also facilitate keratinocyte migration by degrading noncollagenous matrix molecules or by removing damaged basement membrane. It is also tempting to speculate that stromelysin- 2 is involved in the activation of cosecreted procollagenase $(12,13,40)$. Since it is produced by proliferating cells, stromelysin-1 is probably not involved in reepithelialization per se but rather is needed for restructuring the newly formed basement membrane.

In conclusion, our studies indicate that the programmed expression of several distinct matrix metalloproteinases is an important feature of cutaneous wound healing and also offer the possibility that their over-expression is relevant to the pathogenesis of chronic ulcers. While our work has thus far been limited to the skin, one must speculate upon whether ulcerative conditions of other organ systems, for example, gastrointestinal ulcers, involve the similar expression of metalloproteinases by the injured epithelium.

\section{Acknowledgments}

We thank Dr. Juha Kere for advice on PCR methodology, Dr. Elise Chang for her pathology expertise, Dr. Markku Kurkinen for the stromelysin-1 cDNA, and Jill Roby and Teresa Tolley for excellent technical assistance.

This work was supported by grants AR35805, HL29594, HL-48762, and DK38111 from the National Institutes of Health. U. K. SaarialhoKere is the recipient of a Dermatology Foundation Fellowship Award and acknowledges partial support from The Finnish Cultural Foundation.

\section{References}

1. McCachren, S. S. 1991. Expression of metalloproteinases and metalloproteinase inhibitor in human arthritic synovium. Arthritis Rheum. 34:1085-1093

2. Pelletier, J. P., M. P. Faure, J. A. DiBattista, S. Wilhelm, D. Visco, and J. Martel-Pelletier. 1993. Coordinate synthesis of stromelysin, interleukin-1, and oncogene proteins in experimental osteoarthritis. An immunohistochemical study. Am. J. Pathol. 146:95-105.

3. Matrisian, L. M. 1990. Metalloproteinases and their inhibitors in matrix remodeling. Trends Genet. 6:121-125.

4. Chin, J. R., G. Murphy, and Z. Werb. 1985. Stromelysin, a connective tissue degrading metalloendopeptidase secreted by stimulated rabbit synovial fibroblasts in parallel with collagenase. J. Biol. Chem. 260:12367-12376.

5. Muller, D., B. Quantin, M.-C. Gesnel, R. Millon-Collard, J. Abecassis, and R. Breathnach. 1988. The collagenase gene family in humans consists of at least four members. Biochem. J. 253:187-192.

6. Windsor, L. J., H. Grenett, B. Birkedal-Hansen, M. K. Bodden, J. A. Engler, and H. Birkedal-Hansen. 1993. Cell type-specific regulation of SL-1 and SL-2 genes. Induction of the SL-2 gene but not the SL-1 gene by human keratinocytes in response to cytokines and phorbol esters. J. Biol. Chem. 268:17341-17347.

7. Sirum, K. L., and C. E. Brinckerhoff. 1989. Cloning of the genes for human stromelysin and stromelysin 2: differential expression in rheumatoid synovial fibroblasts. Biochemistry 28:8691-8698.

8. Murphy, G., M. I. Cockett, R. V. Ward, and A. J. P. Docherty. 1991. Matrix metalloproteinase degradation of elastin, type IV collagen and proteoglycan. A quantitative comparison of the activities of $95 \mathrm{kDa}$ and $75 \mathrm{kDa}$ gelatinases, stromelysins-1 and -2 and punctuated metalloproteinase (PUMP). Biochem. J. 277:277-279.

9. Brinckerhoff, C. E., K. L. Sirum-Connolly, M. J. Karmilowicz, and D. Auble. 1992. Expression of stromelysin and stromelysin-2 in rabbit and human fibroblasts. Matrix. 1(Suppl.):165-175.

10. Saarialho-Kere, U. K., E. S. Chang, H. G. Welgus, and W. C. Parks 1992. Distinct localization of collagenase and TIMP expression in wound healing associated with ulcerative pyogenic granuloma. J. Clin. Invest. 90:1952-1957.

11. Saarialho-Kere, U. K., S. O. Kovacs, A. P. Pentland, J. E. Olerud, H. G Welgus, and W. C. Parks. 1993. Cell-matrix interactions modulate interstitial collagenase expression by human keratinocytes actively involved in wound healing. J. Clin. Invest. In press.

12. Murphy, G., M. I. Cockett, P. E. Stephens, B. J. Smith, and A. J. P. Docherty. 1987. Stromelysin is an activator of procollagenase. Biochem. J. 248:265-268.

13. He, C. S., S. M. Wilhelm, A. P. Pentland, B. L. Marmer, G. A. Grant, A. Z. Eisen, and G. I. Goldberg. 1989. Tissue cooperation in a proteolytic cascade activating human interstitial collagenase. Proc. Natl. Acad. Sci. USA. 86:26322636.

14. Prosser, I. W., K. R. Stenmark, M. Suthar, E. C. Crouch, R. P. Mecham, and W. C. Parks. 1989. Regional heterogeneity of elastin and collagen gene expression in intralobar arteries in response to hypoxic pulmonary hypertension as demonstrated by in situ hybridization. Am. J. Pathol. 135:1073-1088.

15. Goldberg, G. I., S. M. Wilhelm, A. Kronberger, E. A. Bauer, G. A. Grant, and A. Z. Eisen. 1986. Human fibroblast collagenase. Complete primary structure and homology to an oncogene transformation-induced rat protein. J. Biol. Chem. 261:6600-6605.

16. Saus, J., S. Quinones, Y. Otani, H. Nagase, E. D. Harris, and M. Kurkinen. 1988. The complete primary structure of human matrix metalloproteinase-3. $J$. Biol. Chem. 263:6742-6745.

17. Saarialho-Kere, U. K., E. S. Chang, H. G. Welgus, and W. C. Parks. 1993. Expression of interstitial collagenase, $92 \mathrm{kDa}$ gelatinase, and TIMP-1 in granuloma annulare and necrobiosis lipoidica diabeticorum. J. Invest. Dermatol. 100:335-342.

18. Wilhelm, S. M., I. E. Collier, A. Kronberger, A. Z. Eisen, B. L. Marmer, G. A. Grant, E. A. Bauer, and G. I. Goldberg. 1987. Human skin fibroblast stromelysin: structure, glycosylation, substrate specificity, and differential expression in normal and tumorigenic cells. Proc. Natl. Acad. Sci. USA. 84:6725-6729.

19. Saarialho-Kere, U. K., H. G. Welgus, and W. C. Parks. 1993. Divergent mechanisms regulate interstitial collagenase and $92 \mathrm{kDa}$ gelatinase expression in human monocytic-like cells exposed to bacterial endotoxin. J. Biol. Chem. 268:17354-17361.

20. Parks, W. C., H. Secrist, L. C. Wu, and R. P. Mecham. 1988. Developmental regulation of tropoelastin isoforms. J. Biol. Chem. 263:4416-4423.

21. Pentland, A. P., S. C. Jacobs, M. Mahoney, and M. J. Holzman. 1990. Ultraviolet light potentiates histamine-induced release of prostaglandin in cultured human keratinocytes: a mechanism for irradiation erythema. J. Clin. Invest. 86:566-574.

22. Shapiro, S. D., E. J. Campbell, D. K. Kobayashi, and H. G. Welgus. 1990 Immune modulation of metalloproteinase production in human macrophages. Se lective pretranslational suppression of interstitial collagenase and stromelysin biosynthesis by interferon- $\gamma$. J. Clin. Invest. 86:1204-1210.

23. Ståhle-Bäckdahl, M., and W. C. Parks. 1993. $92 \mathrm{kDa}$ gelatinase is actively expressed by eosinophils and secreted by neutrophils in invasive squamous cell carcinoma. Am. J. Pathol. 142:995-1000.

24. Pulford, K. A. F., E. M. Rigney, K. J. Micklem, W. P. Stross, K. C. Gatter, and D. Y. Mason. 1989. KP1: a new monoclonal antibody that detects a monocyte/macrophage associated antigen in routinely processed tissue sections. J. Clin. Pathol. 42:414-421.

25. Cooper, T. W., E. A. Bauer, and A. Z. Eisen. 1982. Enzyme-linked immunosorbent assay for human skin collagenase. Collagen Relat. Res. 3:205211.

26. Hasty, K. A., T. F. Pourmotabbed, G. I. Goldberg, T. J. P., D. G. Spinella, R. M. Stevens, and C. L. Mainardi. 1990. Human neutrophil collagenase. A distinct gene product with homology to other matrix metalloproteinases. J. Biol. Chem. 265:11421-11424.

27. Ståhle-Bäckdahl, M., B. D. Sudbeck, A. Z. Eisen, H. G. Welgus, and W. C. Parks. 1992. Expression of $92 \mathrm{kDa}$ type IV collagenase by eosinophils associated with basal cell carcinoma. J. Invest. Dermatol. 99:497-503.

28. Werb, Z., P. M. Tremble, O. Behrendtsen, E. Crowley, and C. H. Damsky. 1989. Signal transduction through the fibronectin receptor induces collagenase and stromelysin gene expression. J. Cell Biol. 109:877-889. 
29. Herron, G. S., Z. Werb, K. Dwyer, and M. J. Banda. 1986. Secretion of metalloproteinases by stimulated capillary endothelial cells. I. Production of procollagenase and prostromelysin exceeds expression of proteolytic activity. $J$. Biol. Chem. 261:2810-2813.

30. Welgus, H. G., E. J. Campbell, J. D. Cury, A. Z. Eisen, R. M. Senior, S. M. Wilhelm, and G. I. Goldberg. 1990. Neutral metalloproteinases produced by human mononuclear phagocytes. Enzyme profile, regulation, and expression during cellular development. J. Clin. Invest. 86:1496-1502.

31. Stenn, K. S., and R. Malhotra. 1992. Epithelialization. In Wound Healing: Biochemical and Clinical Aspects. I. K. Cohen, R. F. Diegelmann, and W. J. Lindblad, Editors. W. B. Saunders Co., Philadelphia. 115-127.

32. Pellegrini, G., M. De Luca, G. Orecchia, F. Balzac, O. Cremona, P. Savoia, R. Cancedda, and P. C. Marchisio. 1992. Expression, topography, and function of integrin receptors are severely altered in keratinocytes from involved and uninvolved psoriatic skin. J. Clin. Invest. 89:1783-1795.

33. Symington, B. E., Y. Takada, and W. G. Carter. 1993. Interaction of integrins $\alpha 3 \beta 1$ and $\alpha 2 \beta 1$ : potential role in keratinocyte intercellular adhesion. $J$. Cell Biol. 120:523-535.

34. MacNaul, K. L., N. Chartrain, M. Lark, M. J. Tocci, and N. I. Hutchinson. 1990. Discoordinate expression of stromelysin, collagenase and tissue inhibitor of metalloproteinases-1 in rheumatoid synovial fibroblasts. Synergistic effects of interleukin-1 and tumor necrosis factor- $\alpha$ on stromelysin expression. J. Biol. Chem. 265:17238-17245.

35. Frisch, S. M., and H. E. Ruley. 1987. Transcription from the stromelysin promoter is induced by interleukin-1 and repressed by dexamathasone. J. Biol. Chem. 262:16300-16304.

36. Matrisian, L. M., N. Gleichenhaus, M. C. Gesnel, and R. Breathnach. 1985. Epidermal growth factor and oncogenes induce transcription of the same cellular mRNA in rat fibroblasts. EMBO (Eur. Mol. Biol. Organ.) J. 4:14351440.

37. Kerr, L. D., J. T. Holt, and L. M. Matrisian. 1988. Growth factors regulate transin gene expression by c-fos-dependent and c-fos-independent pathways. Science (Wash. DC). 242:1424-1427.

38. Matrisian, L. M. 1992. The matrix-degrading metalloproteinases. BioEssays. 14:455-463.

39. Edwards, D. R., G. Murphy, J. J. Reynolds, S. E. Whitham, A. J. P. Docherty, P. Angel, and J. K. Heath. 1987. Transforming growth factor modulates the expression of collagenase and metalloproteinase inhibitor. EMBO (Eur. Mol. Biol. Organ.) J. 6:1899-1904.

40. Unemori, E. N., M. J. Bair, E. A. Bauer, and E. P. Amento. 1991. Stromelysin expression regulates collagenase activation in human fibroblasts. J. Biol. Chem. 266:23477-23482. 